Methods. 2008 June ; 45(2): 99-100. doi:10.1016/j.ymeth.2008.06.002.

\title{
Guest Editors' Introduction
}

\author{
Shoukhrat Mitalipov and \\ Oregon National Primate Research Center, Oregon Stem Cell Center, Department of Obstetrics \\ and Gynecology, Oregon Health \& Science University, 505 NW 185th Avenue, Beaverton, OR \\ 97006, USA, E-mail address: mitalipo@ohsu.edu \\ Don P. Wolf \\ Division of Reproductive Sciences, Oregon National Primate Research Center, 505 N.W. 185th \\ Avenue, Beaverton, OR 97006, USA, E-mail address: wolfd@ohsu.edu
}

\section{Methods in stem cell research}

Each of approximately 220 specialized cell types that compose a mammalian organism is branched out from stem cells. A fertilized egg or zygote, which stands at the very origin of each organism, divides and produces stem cells that build tissues and organs of our adult bodies. Thus, stem cells, depending on the source, have the potential to differentiate to all, few, or one cell type of an organism. In an adult body, they supply the cells that replenish worn out, damaged, and diseased tissues as we age. Because stem cells are so versatile, they could potentially be used to treat and cure a variety of diseases and injuries, including Parkinson's disease, stroke, and diabetes.

The stem cell research field has been significantly advanced in the past decade by successes achieved in the identification and derivation of stem cell populations from various sources, in genetics and epigenetics of stem cells, and in their manipulation into differentiated phenotypes, as well as transplantation technology. The foundation of these developments is the development of robust and repeatable protocols that promote stem cell research and its applications to a general field of researchers. Although the majority of peer-reviewed research articles describe general methods, it is often difficult for beginners to a specific research technique to replicate these experiments by following sketchy protocols. For these reasons, this issue of Methods encompasses a selection of excellent articles from well-known experts in the filed featuring step-by-step protocols for isolation, characterization, and directed differentiation of stem cells.

Somatic cell nuclear transfer (SCNT) is an essential approach to studying epigenetic mechanisms of reprogramming of somatic cells back into an embryonic state. However, SCNT is a technically challenging and inefficient procedure, precluding its successful application in many beginner laboratories. The article by Markoulaki, Meissner, and Jaenisch [1] provides a detailed description of SCNT in the mouse and the derivation of embryonic stem cells (ESCs) from embryos generated by this technique.

Tissue-specific adult stem cells can be found in many adult organs and tissues, such as brain, gut, lung, liver, adipose tissue, and bone marrow. Adult stem cells represent a rare population of cells that retain an ability to differentiate into various cell types of their tissue of origin.

\footnotetext{
Publisher's Disclaimer: This is a PDF file of an unedited manuscript that has been accepted for publication. As a service to our customers we are providing this early version of the manuscript. The manuscript will undergo copyediting, typesetting, and review of the resulting proof before it is published in its final citable form. Please note that during the production process errors may be discovered which could affect the content, and all legal disclaimers that apply to the journal pertain.
} 
However, recent studies have demonstrated that some adult stem cells also have the capacity to differentiate into multiple cell types representing mesoderm, endoderm, and ectoderm. The article by Bunnell et al. [2] describes methods for the isolation, expansion, and differentiation of adipose-derived stem cells and their potential for tissue engineering applications. Martin [3] provides an overview of the recent progress in adult lung stem cells, including technical aspects of isolation, characterization, and differentiation, and discusses perspectives for future regenerative therapies in depth. The genetic stability of stem cells destined for therapeutic use is important, given that some chromosomal abnormalities often associated with tumorigenesis are accumulated in human ESCs during long-term in vitro propagation. The development of robust cytogenetic screening techniques will be an important advancement toward the clinical application of human ESCs. In this issue, the article by Meisner and Johnson [4] describes the methods for cytogenetic analysis of human ESCs using G-banding followed by fluorescence in situ hybridization (FISH).

One of the challenges before clinical transplantation studies can begin is to gain a better understanding of the molecular requirements for promoting directed differentiation of stem cells into populations of functional replacement cells, tissues, and organs. A number of strategies for step-wise induction of differentiation have been developed, including neural, hematopoietic, and cardiac differentiation. This issue of Methods describes some of these diverse methods. Differentiation of human pluripotent stem cells into cells of the neural lineage is a central focus of an article by Schwartz et al. [5]. In this review, the authors describe methods for the generation of divergent neural cells such as dopaminergic neurons, retinal neurons, ventral motoneurons, and oligodendroglial progenitors. The article by Orlovskaya et al. [6], from the Khaldoyanidi laboratory, describes methods for deriving hematopoietic cells from ESCs using hematopoiesis-supportive feeder cells, cocktails of soluble hematopoietic growth factors, and a variety of matrices. This is followed by an article from Pucéat [7] outlining technical aspects of cardiac differentiation of ESCs. The final article, by Salvador et al. [8], from the Strauss laboratory, demonstrates the ability of ESCs to generate germ cells and oocytelike cells upon directed in vitro differentiation.

In addition to detailed methods, each article includes excellent discussions and reviews of the up-to-date literature on the subject.

\section{References}

1. Markoulaki S, Meissner A, Jaenisch R. Methods. 2008;(this issue)

2. Bunnell BA, Flaat M, Gagliardi C, Patel B, Ripoll C. Methods. 2008;(this issue)

3. Martin U. Methods. 2008; (this issue)

4. Faxon Meisner L, Johnson JA. Methods. 2008;(this issue)

5. Schwartz PH, Brick DJ, Stover AE, Loring JF, Müller FJ. Methods. 2008;(this issue)

6. Orlovskaya I, Schraufstatter I, Loring J, Khaldoyanidi S. Methods. 2008;(this issue)

7. Pucéat M. Methods. 2008; (this issue)

8. Salvador LM, Silva CP, Kostetskii I, Radice GL, Strauss JF III. Methods. 2008;(this issue) 